\title{
HIF-1 is involved in the negative regulation of AURKA expression in breast cancer cell lines under hypoxic conditions
}

\author{
Daniele Fanale • Viviana Bazan · Lidia Rita Corsini • \\ Stefano Caruso $\cdot$ Lavinia Insalaco $\cdot$ Marta Castiglia $\cdot$ \\ Giuseppe Cicero $\cdot$ Giuseppe Bronte $\cdot$ Antonio Russo
}

Received: 19 June 2013/Accepted: 20 July 2013/Published online: 8 August 2013

(C) Springer Science+Business Media New York 2013

\begin{abstract}
Numerous microarray-based gene expression studies performed on several types of solid tumors revealed significant changes in key genes involved in progression and regulation of the cell cycle, including AURKA that is known to be overexpressed in many types of human malignancies. Tumor hypoxia is associated with poor prognosis in several cancer types, including breast cancer (BC). Since hypoxia is a condition that influences the expression of many genes involved in tumorigenesis, proliferation, and cell cycle regulation, we performed a microarray-based gene expression analysis in order to identify differentially expressed genes in BC cell lines exposed to hypoxia. This analysis showed that hypoxia induces a down-regulation of AURKA expression. Although hypoxia is a tumor feature, the molecular mechanisms that regulate AURKA expression in response to hypoxia in $\mathrm{BC}$ are still unknown. For the first time, we demonstrated that HIF-1 activation downstream of hypoxia could drive AURKA down-regulation in BC cells. In fact, we found that siRNA-mediated knockdown of HIF- $1 \alpha$ significantly reduces the AURKA down-regulation in $\mathrm{BC}$ cells under hypoxia. The aim of our study was to obtain new insights into AURKA transcriptional regulation in
\end{abstract}

Daniele Fanale and Viviana Bazan have contributed equally to this work.

Electronic supplementary material The online version of this article (doi:10.1007/s10549-013-2649-0) contains supplementary material, which is available to authorized users.

D. Fanale · V. Bazan - L. R. Corsini - S. Caruso $\cdot$ L. Insalaco $\cdot$

M. Castiglia · G. Cicero · G. Bronte · A. Russo ( $\square)$

Section of Medical Oncology, Department of Surgical,

Oncological and Stomatological Sciences, University

of Palermo, Via del Vespro 129, 90127 Palermo, Italy

e-mail: antonio.russo@usa.net hypoxic conditions. Luciferase reporter assays showed a reduction of AURKA promoter activity in hypoxia. Unlike the previous findings, we hypothesize a new possible mechanism where HIF-1, rather than inducing transcriptional activation, could promote the AURKA down-regulation via its binding to hypoxia-responsive elements into the proximal region of the AURKA promoter. The present study shows that hypoxia directly links HIF-1 with AURKA expression, suggesting a possible pathophysiological role of this new pathway in BC and confirming HIF-1 as an important player linking an environmental signal to the AURKA promoter. Since AURKA down-regulation overrides the estrogen-mediated growth and chemoresistance in $\mathrm{BC}$ cells, these findings could be important for the development of new possible therapies against BC.

Keywords AURKA - Breast cancer - Cell cycle . HIF-1 $\alpha \cdot$ Hypoxia

\section{Introduction}

Breast cancer (BC) is one of the most common cancers and a major cause of death among women worldwide [1]. Advances in molecular characterization of tumor by microarray profiling allowed the identification of five distinct molecular subtypes of $\mathrm{BC}$ which have led to the identification of a large number of novel targets and, in parallel, to the development of multiple approaches for anticancer therapy $[2,3]$. Numerous microarray-based gene expression studies performed on several types of solid tumors revealed significant changes in key genes involved in progression and regulation of the cell cycle [4, 5]. Aberrations in genetic pathways controlling cell cycle cause abnormal cell growth, senescence, and apoptosis, 
inducing malignant transformation of cells [6, 7]. Aurora kinases are a novel family of mitotic serine/threonine kinases involved in different processes of cell cycle control [8]. Aurora kinase A (AURKA), whose expression is cell cycle dependent, is mainly involved in centrosome maturation, spindle assembly, and chromosome segregation, and it is associated with several co-activators such as BORA, TPX2, Ajuba (JUB), TACC1, and GADD45 $\alpha$ that drive the localization, activation, and substrate preference during cell division [9, 10]. AURKA is overexpressed in many types of human malignancies, such as breast, bladder, ovarian, colorectal, pancreatic, and gastric cancers [11-13]. This overexpression correlates with tumorigenesis, metastasis, and chemoresistance, confirming the pro-survival function of AURKA in cancer cells. Aurora-A overexpression may be achieved not only by gene amplification but also by other mechanisms such as transcription activation or suppression of protein degradation. Several studies, carried out on different tumors, showed that $A U$ $R K A$ transcription may be induced by HIF-1 $\alpha$, E2F3, E4TF1, TRAP220/MED1, and c-Myc [14-16]. However, the mechanism of transcriptional regulation of AURKA remains largely unknown, especially in BC.

In recent years, small molecules with an inhibiting action toward the aurora kinase family were developed. These molecules can act by blocking the protein-protein interaction between the aurora kinase and its substrates or blocking the ATP-binding site of the serine threonine kinase [17].

A typical feature of the microenvironment of several solid tumors is the hypoxia [18] that influences the expression of various proteins involved in proliferation and cell cycle progression [19-21]. The stabilization of the hypoxia-inducible transcription factor, HIF-1, is a crucial event that induces changes in the expression of many genes implicated in the growth and survival of neoplastic cells [22, 23]. HIF-1 is made up of two subunits, $\alpha$ and $\beta$ [24]. Subunit $\beta$ is constitutively expressed and its activity is oxygen independent. The expression of the subunit $\alpha$ is induced by cell hypoxia and kept at low levels in a great many cells in normoxia $[25,26]$. Under normoxic conditions, HIF- $1 \alpha$ is targeted for degradation through the hydroxylation of its oxygen-dependent degradation domain (ODDD) by prolyl hydroxylases (PHDs) [27]. Von Hippel-Lindau protein (pVHL), which is a component of the E3 ubiquitin ligase complex, recognizes prolylhydroxylated HIF- $1 \alpha$ and drives its polyubiquitination and proteasomal degradation. Under hypoxia, HIF-1 $\alpha$ subunit is stabilized and dimerizes with HIF-1 $\beta$, translocates to the nucleus, and activates transcription of target genes via binding to hypoxia-responsive elements (HREs) [22, 28]. HIF-1 induces the expression of more than 100 genes [29], including the vascular endothelial growth factor $(V E G F)$, glycolytic enzymes [30], and various genes involved in proliferation and cell cycle progression, to insure the cancer cell survival [20, $31,32]$. Recently, the HIF-1 role as a repressor in response to hypoxia has been shown in several tumors. In 2005, Chen et al. [33] showed that the suppression of the $C A D$ expression under hypoxia is HIF- $1 \alpha$ dependent in human colon cancer cells, inducing cell proliferation arrest. Furthermore, Feige et al. [34] reported that HIF-1 represses the expression of the MITF oncogene through induction of the transcriptional repressor DEC1 in melanoma and clear cell sarcoma cells. In addition, in 2011, Ryu et al. [35] described the HIF-1 role as transcriptional repressor of the estrogen receptor alpha (ER $\alpha)$ gene in MCF-7 and T47D human BC cells under hypoxia. The authors showed that hypoxia induces HIF- $1 \alpha$-mediated repression of the ESR1 gene at the transcriptional level, promoting hormone insensitivity in the tumor microenvironment.

Although hypoxia is a typical tumor condition, the molecular mechanisms that regulate AURKA expression in response to hypoxic condition in $\mathrm{BC}$ are still unknown. Therefore, the aim of our study was to obtain new insights on AURKA regulation in $\mathrm{BC}$ cell lines under hypoxia, by evaluating the possible HIF-1 role in transcriptional control of AURKA expression. In this work, we hypothesize that hypoxia down-regulates AURKA expression in a HIF-1 $\alpha$-dependent manner, suggesting, for the first time, a novel potential role of HIF-1 as transcriptional repressor of AURKA in BC cells.

\section{Methods}

\section{Cell culture}

Human BC cell lines, MCF-7, MDA-MB-231, and SK-Br3, purchased from the American Type Culture Collection (Rockville, MD, USA), were cultured in Dulbecco's Modified Eagle Medium (DMEM:F12) supplemented with $10 \%$ fetal bovine serum (FBS) and antibiotics $(100 \mathrm{U} / \mathrm{mL}$ penicillin and $50 \mathrm{mg} / \mathrm{mL}$ streptomycin) (Invitrogen, Carlsbad, CA, USA).

Cell lines were cultured at $80 \%$ confluence in a normoxic atmosphere of $16 \% \mathrm{O}_{2}, 79 \% \mathrm{~N}_{2}$, and $5 \% \mathrm{CO}_{2}$ (by volume) for $24 \mathrm{~h}$. Then, medium was renewed and cells were further cultured under normoxia or hypoxia ( $3 \% \mathrm{O}_{2}, 87 \% \mathrm{~N}_{2}, 5 \% \mathrm{CO}_{2}$, by volume) at two different time points, 24 and $48 \mathrm{~h}$.

\section{Microarray analysis}

Microarray analysis was performed as previously described [36]. Total RNA was extracted according to the manufacturer's protocol (Affymetrix, Santa Clara, CA). Fragmented cRNA was hybridized using a human oligonucleotide array U133 Plus 2.0 (Genechip Affymetrix, Santa Clara, CA). 
Washing and staining were performed through Affymetrix GeneChip Fluidic Station 450. Probe arrays were scanned using Affymetrix GeneChip Scanner3000 G7 enabled for High-Resolution Scanning. Two biological replicates were performed for each experimental condition. Images were extracted with the GeneChip Operating Software (Affymetrix GCOS v1.4). Quality control of the arrays was performed using the AffyQCReport software [37].

\section{Statistical analysis}

For statistical analysis, the background subtraction and normalization of probe set intensities were performed using the method of Robust Multiarray Analysis (RMA) described by Irizarry et al. [38]. To identify differentially expressed genes (DEGs), gene expression intensity was compared using a moderated $t$ test and a Bayes smoothing approach developed for a low number of replicates [39]. To correct for the effect of multiple testing, the false discovery rate was estimated from $P$ values derived from the moderated $t$ test statistics [40]. The analysis was performed using the affylmGUI Graphical User Interface for the Limma Microarray Package (Bioconductor Software) [41].

Significant differences were determined by Student's $t$ test. $P<0.05$ was considered to be statistically significant.

\section{Microarray data analysis}

Hierarchical cluster (HCA) and heat map analyses were performed using the MultiExperiment Viewer (MeV v4.8) program of TM4 Microarray Software Suite.

The Gene Set Analysis Toolkit was used to investigate the biological significance of a set of genes represented by the specific expression pattern during the progression of cell cycle. DEGs were analyzed according to predefined pathways annotated by KEGG [42] and Biocarta bioinformatic resources. For an over-represented KEGG or Biocarta pathway, a cutoff $P$ value of 0.01 was selected. All shown values are in logarithm scale.

\section{Quantitative real-time PCR (qRT-PCR) and RT-PCR}

Total cellular RNA was extracted using RNeasy Mini Kit (Qiagen Inc., Valencia, CA, USA). Then, RNA was controlled through 2100 Bioanalyzer (Agilent Technologies, Santa Clara, CA, USA) and quantified through the spectrophotometer NanoDrop ND-1000 (CELBIO). For AURKB, $A U R K A$, and $H I F-1 \propto$ mRNA detection, 2 ng of total RNA was reverse transcribed into single-stranded cDNA using high capacity cDNA reverse transcription kit (Applied Biosystems, Foster City, CA, USA) according to the vendor's instructions. Gene primers for AURKA, AURKB, and $H I F-1 a$ were purchased from Applied Biosystems (TaqMan gene expression assay). Quantitative real-time PCR (qRTPCR) was performed with the ABI PRISM 7900 sequence detection system (Applied Biosystems, Foster City, CA, USA) using SDS software version 2.1. The reactions were performed in triplicate and the results were normalized using Human $\beta$-actin Pre-Developed TaqMan assay reagents (Applied Biosystems). Changes in the target mRNA content were determined using a comparative CT method (ABI User Bulletin No. 2). An average CT value for each RNA was obtained for triplicate reactions. A reverse transcription polymerase chain reaction (RT-PCR) was also performed in order to confirm the results previously obtained with qRTPCR. The data were evaluated in $2 \%$ agarose gel.

\section{Western blotting (WB)}

Cells were lysed using the complete Lysis-M reagent set (Roche, Mannheim Germany). Protein concentration was measured using Quick Start Bradford (Bio-Rad Laboratories, Hercules, CA). $80-100 \mu \mathrm{g}$ of total protein lysate was separated on $10 \%$ polyacrylamide gel under denaturing conditions and immunoblotted into nitrocellulose membrane. The following antibodies (Abs) were used: anti-HIF$1 \alpha$ rabbit (Bethyl Laboratories, Montgomery, USA); antiphospho-aurora A (Thr288) (CD39D8) (Cell Signaling Technology, Boston, MA, USA); anti-VEGF (147); antiARK1(N-20); and anti-GAPDH(6C5) (Santa Cruz Biotechnology, Santa Cruz, CA, USA).

\section{RNA interference and stabilization of HIF-1 $\alpha$}

The small-interfering RNA (siRNA) oligonucleotides specific for human HIF-1 $\alpha$ were purchased from Thermo Scientific Dharmacon ${ }^{\circledR}$ (ON-TARGETplus SMARTpool L-004018-00-0005, Human HIF1A, NM_181054, 5 nmol). ON-TARGETplus SMARTpool siRNA is a mixture of 4 siRNAs (provided as a single reagent) that target the following HIF-1 $\alpha$ sequences: GAACAAAUACAUGGGA UUA, AGAAUGAAGUGUACCCUAA, GAUGGAAGCA CUAGACAAA, and CAAGUAGCCUCUUUGACAA. The cells were cultured in six-well culture dishes, maintained in $2 \mathrm{~mL}$ of DMEM medium, and transfected by adding $5 \mu \mathrm{M}$ siRNA (siHIF-1 $\alpha)$ and DharmaFECT ${ }^{\circledR}$ four according to manufacturer's instructions. After 24-48 h (for mRNA analysis) or 48-96 $\mathrm{h}$ (for protein analysis) of incubation with siRNA and transfection reagent, the cells were exposed to hypoxia for 24 and $48 \mathrm{~h}$. ON-TARGETplus Non-targeting Control Pool (Thermo Scientific Dharmacon ${ }^{\circledR}$ ) was used as a siRNA negative control (non-specific scrambled siRNA) (data not shown).

Furthermore, cells were incubated in the absence or the presence of HIF hydroxylase inhibitor, dimethyloxalylglycine (DMOG) (Sigma-Aldrich, St. Louis, MO), for 24 
and $48 \mathrm{~h}$, at a final concentration of $1 \mathrm{mM}$. Subsequently, cells were lysed and protein extracts were analyzed by Western blot.

\section{Chromatin immunoprecipitation (ChIP)}

Immunoprecipitation was performed using the ChIP Assay Kit (Millipore, Temecula, CA) according to the manufacturer's protocol. $1 \times 10^{6}$ cells were cultured on a $10-\mathrm{cm}$ culture dish under normoxia and hypoxia (24 and $48 \mathrm{~h}$ ). The cells then were treated with a solution of PBS and $1 \%$ formaldehyde, and incubated for $8 \mathrm{~min}$ at $37{ }^{\circ} \mathrm{C}$ in order to cross-link histones to DNA. Cells were collected (4 min; $4{ }^{\circ} \mathrm{C} ; 4,000 \mathrm{rpm}$ ) and sonicated in order to shear DNA to lengths between 200 and 1,000 bp. Soluble chromatin was immunoprecipitated with $5 \mathrm{mg}$ of HIF- $1 \alpha$ antibody (Santa Cruz Biotechnology, Santa Cruz, CA, USA) overnight at $4{ }^{\circ} \mathrm{C}$. DNA-protein immune complexes were eluted, reverse cross-linked, and DNA was recovered by phenol/ chloroform extraction and ethanol precipitation. The binding of HIF- $1 \alpha$ to the AURKA promoter region $-336 /-236$ containing the three putative HREs (HRE-1: $-336 /-332$; HRE-2: -323/-319; HRE-3: -240/-236) was determined by PCR using the following primers: forward $5^{\prime}$-AGTC GTTTCTGTGGTTTTCTC- $3^{\prime}$ and reverse $5^{\prime}$-GAGATAA AGTCCAAGGAGGTGAAC- $3^{\prime}$. Furthermore, an AURKA promoter region without HREs was used as a control using the following primers: forward 5'-CTGTTCTATCCGGT CTCTTCACTT- $3^{\prime}$ and reverse $5^{\prime}$-TTGGGGATAATTAG GCTTCTGTT- $3^{\prime}$. The PCR conditions were as follows: 5 min at $95{ }^{\circ} \mathrm{C}$; $30 \mathrm{~s}$ at $95{ }^{\circ} \mathrm{C}, 30 \mathrm{~s}$ at $60{ }^{\circ} \mathrm{C}, 40 \mathrm{~s}$ at $72{ }^{\circ} \mathrm{C}$ for 35 cycles; $7 \mathrm{~min}$ at $72{ }^{\circ} \mathrm{C}$.

\section{Luciferase activity assay}

Luciferase assay was performed as previously described by Klein et al. [14] using the luciferase reporter plasmidic construct pGL3-AURKA-Luc. Firefly luciferase reporter plasmid containing the human AURKA promoter (from -986 to +15 ) was generated using the pGL3 basic plasmid (Promega Italia, Milano, Italy). The human AURKA promoter 5 -flanking region containing three putative HREs was amplified by PCR from genomic DNA and the corresponding PCR product was cloned into pGL3 vector at the KpnI and XhoI sites. BC cells were transfected with firefly luciferase vector (pGL3-AURKA-Luc) or with pGL3-basic-Luc empty vector used as a negative control, using Lipofectamine 2000 (Life Technologies). A Renilla luciferase reporter, pRL-TK (Promega), was co-transfected as a control for normalization. After $24 \mathrm{~h}$ of incubation, cells were cultured under normoxia or hypoxia (for 24 and $48 \mathrm{~h}$ ) and then lysed in passive lysis buffer (Promega). Luciferase activity of cell lysates was measured using the
Dual-Luciferase Reporter Assay System Kit (Promega) and the GloMax $^{\circledR} 96$ Microplate Luminometer (Promega) according to the manufacturer's protocol. Normalized data were represented as the ratio of Firefly/Renilla luciferase activities. The shown data represent the mean \pm SD from three independent experiments, each performed in duplicate.

\section{Results}

Gene expression profiling in $\mathrm{BC}$ cells under hypoxia

Considering that hypoxia is a condition that during tumor growth influences the expression of several genes involved in proliferation and cell cycle progression, we first performed a microarray analysis, using Affymetrix platform, in order to compare differential gene expression profiles in MCF-7, MDA-MB-231, and SKBr3 human BC cell lines in response to hypoxic exposure for 24 and $48 \mathrm{~h}$. This work was carried out in order to evaluate the involvement of some genes in molecular pathways related to tumor pathogenesis. This analysis allowed us to obtain, for each examined BC cell line, two lists of DEGs in hypoxia at 24 and $48 \mathrm{~h}$ with respect to normoxia (control). In particular, for this study, the lists were screened considering as significant only the genes with fold change $(M)>|1|$ (logarithm scale) and $P<0.01$. Thus, we obtained six lists of DEGs with respect to the normoxic condition, including after $24 \mathrm{~h}$ of hypoxia 4,019 genes (2,482 down-regulated and 1,537 up-regulated) for MCF-7; 4,742 genes (3,032 down-regulated and 1,710 up-regulated) for MDA-MB231; and 6,970 genes (4,615 down-regulated and 2,355 upregulated) for $\mathrm{SKBr} 3$; and after $48 \mathrm{~h}$ of hypoxia 4,229 genes (2,362 down-regulated and 1,867 up-regulated) for MCF-7; 4,830 genes (1,832 down-regulated and 2,998 upregulated) for MDA-MB-231; and 9,575 genes $(6,287$ down-regulated and 3,288 up-regulated) for SKBr3.

Then, six lists of genes were compared with each other and analyzed in order to identify a set of DEGs common to three BC cell lines (Supplementary Table S1). Using Venn diagrams, we found 270 shared genes (81 down-regulated and 189 up-regulated) that showed a gene expression variation in hypoxia ( 24 and $48 \mathrm{~h}$ ) with respect to normoxia. Furthermore, 725 genes showed an altered expression only in MCF-7, 511 genes in MDA-MB-231, and 2513 genes in SKBr3 (Fig. 1).

Molecular pathways altered in hypoxia

A further series of studies was conducted on the microarray analysis data in order to identify any genes of particular interest. Our attention was focused mainly on the genes involved in proliferation, cell cycle progression, mitosis, 


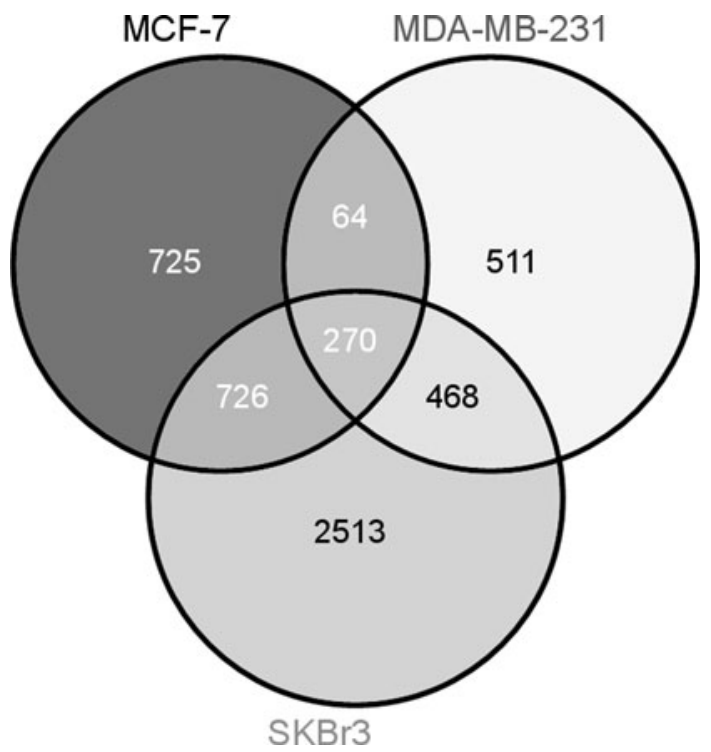

Fig. 1 Venn diagrams summarizing DEGs in breast cancer cell lines in response to hypoxia. The number of total, unique, and common DEGs $(M>|1|$ and $P<0.01)$ is shown. Each Venn diagram includes for each cell line the number of genes (down- and up-regulated) whose expression is altered in hypoxic conditions (for 24 and $48 \mathrm{~h}$ ) with respect to normoxia: 1,785 genes for MCF-7; 1,313 genes for MDA-MB-231; and 3,977 genes for SKBr3. The intersection among three Venn diagrams has allowed the identification of 270 DEGs shared by all three cell lines in response to hypoxia

and response to hypoxia. The integrated analysis resulting from KEGG and Biocarta databases allowed us to identify the main molecular pathways altered in BC cell lines after hypoxic exposure for 24 and $48 \mathrm{~h}$. This analysis indicated that the genes showing a significant variation in expression levels were included in the following three pathways: cell cycle regulation (35 genes), HIF-1 $\alpha$ network (15 genes), and AURKA signaling (12 genes). The DEGs involved in these pathways were grouped in heat maps (Fig. 2). A considerable number of genes involved in proliferation and cell cycle control, through the G1/S and G2/M transitions, exhibited a significantly deregulated expression in all three BC cell lines (Fig. 2a). Among the DEGs in hypoxia, required for G1/S transition, CDC6, CCND1, CCNE2, and $C D K 2$ were tendentially down-regulated, whereas $C D K N 1 A$ (p21 ${ }^{\text {Cip1 }}$ ) was up-regulated. Instead, CDC25A was down-regulated in MCF-7 and SKBr3 cells and upregulated in MDA-MB-231 cells. Moreover, we found that in MCF-7 and SKBr3 cells, hypoxia induces down-regulation of several genes required for $\mathrm{G} 2 / \mathrm{M}$ transition, such as $C C N A 2, C C N B 1, C C N B 2, C D C 2(C D K 1)$, and $C D C 25 C$. The same results were shown by MDA-MB-231 cells under hypoxic conditions for $24 \mathrm{~h}$ (Supplementary Table S2).

In addition, significant increases in expression levels were also observed in key genes involved in HIF- $1 \alpha$ network (Fig. 2b), such as VEGF-A, SLC2A1, JUN, FOS, and other genes encoding for glycolytic enzymes ( $P G K 1$, PFKFB3, HK2, ALDOA) (Supplementary Table S3). Finally, microarray analysis showed a significant variation in expression levels of some genes that regulate the mitosis included in AURKA signaling pathway (Fig. 2c). This analysis revealed that hypoxia induces a noteworthy downregulation of $A U R K A$ expression. Other genes involved in the same pathway, such as $A U R K B, J U B$ (ajuba), and $T P X 2$, were tendentially down-regulated in all three BC cell lines under hypoxic conditions (Supplementary Table S4).

AURKA down-regulation in $\mathrm{BC}$ cells under hypoxia

In particular, our analyses were focused mainly on effects of hypoxia on AURKA expression and molecular mechanisms that regulate this. As previously described, in all three examined $\mathrm{BC}$ cell lines, in response to hypoxia, a downregulation of AURKA expression compared to normoxia (fold changes: -2.19 and -3.55 in MCF-7; -2.56 and -1.51 in MDA-MB-231; and -1.84 and -3.17 in $\mathrm{SKBr} 3$, at 24 and $48 \mathrm{~h}$, respectively) and a concomitant decrease in expression levels of $J U B$ (fold changes: -1.90 and -2.60 in MCF-7; -3.43 and -1.78 in MDA-MB-231; and -1.14 and $-1.65 \mathrm{in} \mathrm{SKBr} 3$, at 24 and $48 \mathrm{~h}$, respectively) were observed. Both TPX2 and AURKB also showed a parallel down-regulation of their expression in hypoxia, except that in MDAMB-231 cells exposed to hypoxia for $48 \mathrm{~h}$ (fold change: +1.22 and +1.20 , respectively). Furthermore, microarray analysis revealed, following hypoxic exposure, significant changes in expression levels of AURKA-related genes that regulate the G2/M transition and mitosis, such as CCNB1, $C C N B 2, C D C 2, C D C 25 B$, and TACC1. All these genes exhibited a negative fold change (M), except $C C N B 2$ $(M=+1.73)$ and $C D C 2(M=+1.19)$ in MDA-MB-231 cells, after hypoxia for $48 \mathrm{~h}$ (Table 1). In order to validate microarray analysis data, we evaluated the AURKA mRNA expression levels in the same $\mathrm{BC}$ cell lines under hypoxic conditions, using qRT-PCR and RT-PCR (Fig. 3a, b). The qRT-PCR analysis confirmed that hypoxia induces a AURKA down-regulation, with an increased reduction of mRNA expression levels after $48 \mathrm{~h}$ of exposure in MCF-7 and SKBr3 cells ( 0.15 -fold and 0.2 -fold, respectively), and with an initial decrease after $24 \mathrm{~h}$ ( 0.25 -fold) followed by a partial expression increase after $48 \mathrm{~h}(0.45$-fold $)$ in MDA-MB-231 cells (Fig. 3a). Similar results were obtained by means of RT-PCR analysis (Fig. 3b). Interestingly, in parallel to AURKA mRNA down-regulation, we observed, through Western blot (WB) analysis, a reduction of AURKA protein levels in MCF-7 and $\mathrm{SKBr} 3$ cells after 24 and $48 \mathrm{~h}$ of hypoxia, compared to the control condition (normoxia). Differently, as demonstrated by microarray analysis, MDA-MB-231 cells showed a reduction in AURKA protein levels after $24 \mathrm{~h}$, with a partial increase in 


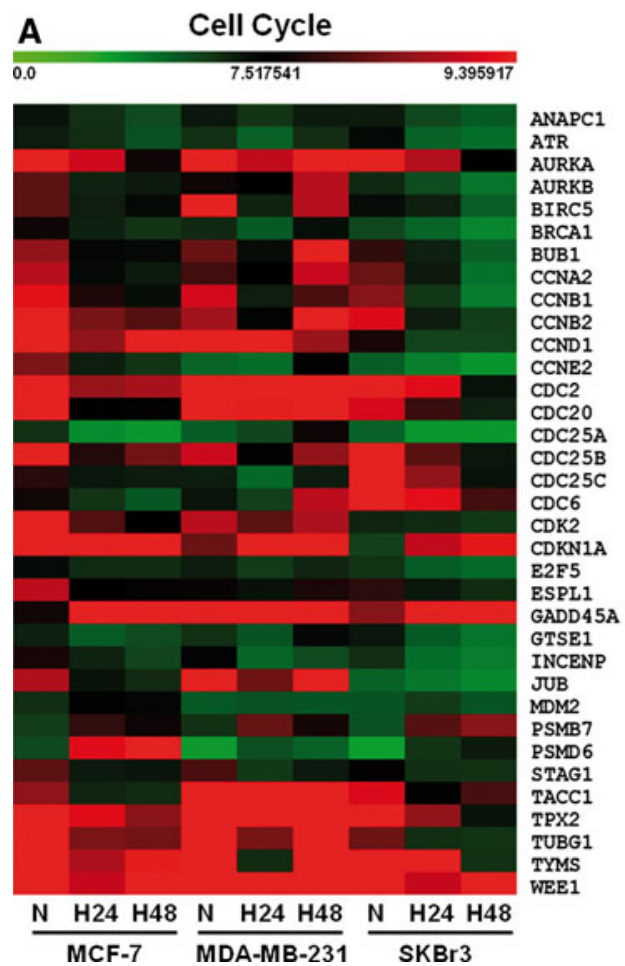

Fig. 2 Heat maps of common DEGs involved in main molecular pathways deregulated in hypoxia. Clustering of common DEGs involved in a cell cycle regulation pathway, b HIF- $1 \alpha$ network, and c AURKA signaling pathway. The heat maps were generated from microarray data reflecting gene expression values in MCF-7, MDAMB-231, and SKBr3 cells exposed to hypoxia $\left(3 \% \mathrm{O}_{2}\right)$ for 24 and $48 \mathrm{~h}$ in comparison to control cells cultured under normoxic conditions $(M>|1|$ and $P<0.01)$. Each row represents the expression levels for a single gene tested for different experimental

the expression after $48 \mathrm{~h}$ of exposure to hypoxia. Consistent with our findings, together with a reduction of the AURKA protein expression, we detected a decrease in expression levels of phospho-aurora A (Thr288) and an increase in HIF$1 \alpha$ and VEGF-A protein levels in BC cells under hypoxia. However, HIF-1 $\alpha$ showed a lower expression level in MDAMB-231 cells exposed to hypoxia for $48 \mathrm{~h}$ (Fig. 3c).

Hypoxia down-regulates AURKA expression in a HIF$1 \alpha$-dependent manner

Since HIF- $1 \alpha$ is a key transcription factor during hypoxia, we investigated its role in down-regulation of AURKA expression in $\mathrm{BC}$ cells exposed to hypoxia. To determine whether AURKA down-regulation was due to the expression of HIF- $1 \alpha$, we evaluated AURKA expression variations in HIF-1 $\alpha$-silenced cells. Therefore, HIF-1 $\alpha$-dependent effects of hypoxia were reversed by silencing HIF- $1 \alpha$ mRNA expression with a specific siRNA pool targeting HIF-1 $\alpha$ (siHIF-1 $\alpha$ ). A non-targeting control pool was used as a siRNA negative control (data not shown). Using qRT-PCR

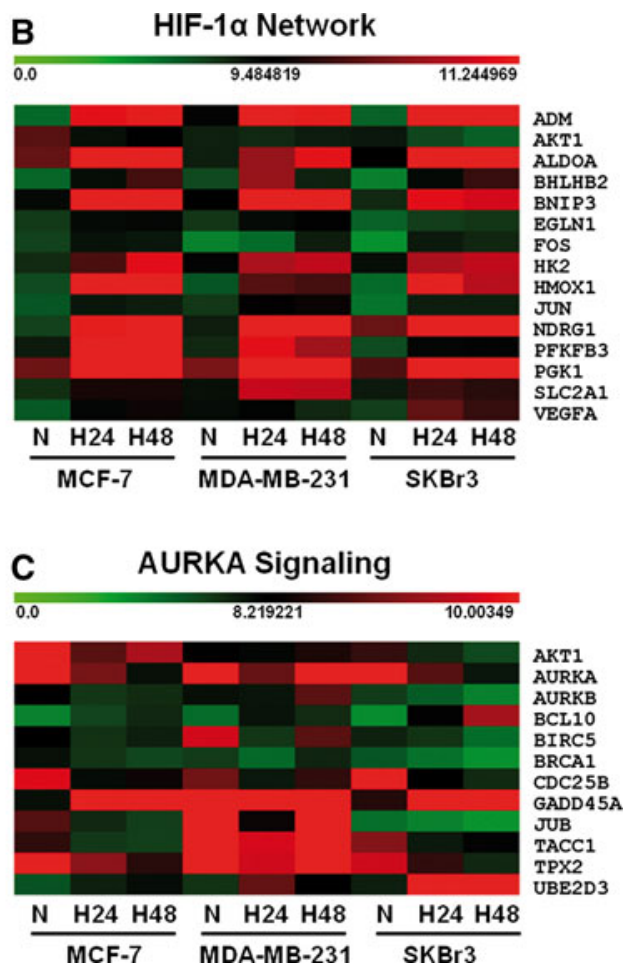

conditions. Each column shows the expression levels for the genes tested for a single experimental condition. The absolute expression value (log scale) of each gene is derived from the mean of two biological replicates. The color scale bar on the top represents signal intensity variations ranging from green (poorly expressed genes) to red (highly expressed genes). Black boxes indicate intermediate expression values. $N$ normoxia; $H 24$ hypoxia for 24 h; $H 48$ hypoxia for $48 \mathrm{~h}$

analysis, specific knockdown of HIF-1 $\alpha$ was confirmed at the mRNA level and a significant increase in AURKA mRNA expression levels was observed in all three analyzed BC cell lines, following HIF-1 $\alpha$ silencing (Fig. 4a). In MCF-7 and SKBr3 cells, knockdown of HIF- $1 \alpha$ induced a greater increase of AURKA expression after $48 \mathrm{~h}$ of hypoxia (from 0.15 -fold to 0.75 -fold and from 0.2 -fold to 0.7 -fold, respectively) in comparison to that found after $24 \mathrm{~h}$ (from 0.45 -fold to 0.65 -fold and from 0.3 -fold to 0.6 -fold, respectively). In MDA-MB-231 cells, a lower increase was observed after $48 \mathrm{~h}$ of hypoxia (from 0.6 -fold to 0.7 -fold) with respect to that detected after $24 \mathrm{~h}$ (from 0.3 -fold to 0.6fold) (Fig. 4a). Similar results, after HIF-1 $\alpha$ silencing, were obtained by means of RT-PCR analysis (Fig. 4b). Specific knockdown of HIF- $1 \alpha$ was also evaluated at the protein level. WB analysis showed a good correlation with data previously obtained. In BC cells, silencing of HIF-1 $\alpha$ by RNA interference induced a significant increase in AURKA and phospho-aurora A (p-AURKA) protein levels after 24 and $48 \mathrm{~h}$ of hypoxia. Greater differences in protein expression were detected in hypoxic condition at $48 \mathrm{~h}$, except that 
Table 1 Effects of hypoxia on expression of genes related to AURKA

\begin{tabular}{|c|c|c|c|c|c|c|c|}
\hline \multirow[t]{2}{*}{ ID Affymetrix } & \multirow[t]{2}{*}{ Gene symbol } & \multicolumn{2}{|l|}{ MCF-7 } & \multicolumn{2}{|c|}{ MDA-MB-231 } & \multicolumn{2}{|l|}{ SKBr3 } \\
\hline & & $\mathrm{M}_{\mathrm{H} 24}$ & $\mathrm{M}_{\mathrm{H} 48}$ & $\mathrm{M}_{\mathrm{H} 24}$ & $\mathrm{M}_{\mathrm{H} 48}$ & $\mathrm{M}_{\mathrm{H} 24}$ & $\mathrm{M}_{\mathrm{H} 48}$ \\
\hline 208079_s_at & AURKA & -2.19 & -3.55 & -2.56 & -1.51 & -1.84 & -3.17 \\
\hline 209464_at & $A U R K B$ & -1.76 & -1.46 & -1.14 & +1.20 & -1.06 & -2.24 \\
\hline 228729_at & $C C N B 1$ & -1.46 & -2.15 & -2.47 & -1.15 & -2.65 & -4.65 \\
\hline 202705_at & CCNB2 & -1.91 & -2.16 & -1.38 & +1.73 & -2.51 & -3.49 \\
\hline 203213_at & $C D C 2$ & -2.00 & -1.88 & -1.12 & +1.19 & -1.52 & -3.74 \\
\hline 201853_s_at & $C D C 25 B$ & -1.97 & -1.42 & -1.87 & -1.31 & -1.93 & -3.27 \\
\hline 225806_at & $J U B$ & -1.90 & -2.60 & -3.43 & -1.78 & -1.14 & -1.65 \\
\hline 200911_s_at & TACC1 & -2.18 & -2.36 & -2.19 & -1.13 & -1.73 & -1.07 \\
\hline 210052_s_at & $T P X 2$ & -1.73 & -2.39 & -1.22 & +1.22 & -1.07 & -2.73 \\
\hline
\end{tabular}

$\mathrm{M}_{\mathrm{H} 24}$ represents the fold change of hypoxia versus normoxia (control) at $24 \mathrm{~h}$. $\mathrm{M}_{\mathrm{H} 48}$ represents the fold change of hypoxia versus normoxia at $48 \mathrm{~h}$. All showed fold change $(M)$ values are in logarithm scale. $M>|1|$ and $P<0.01$
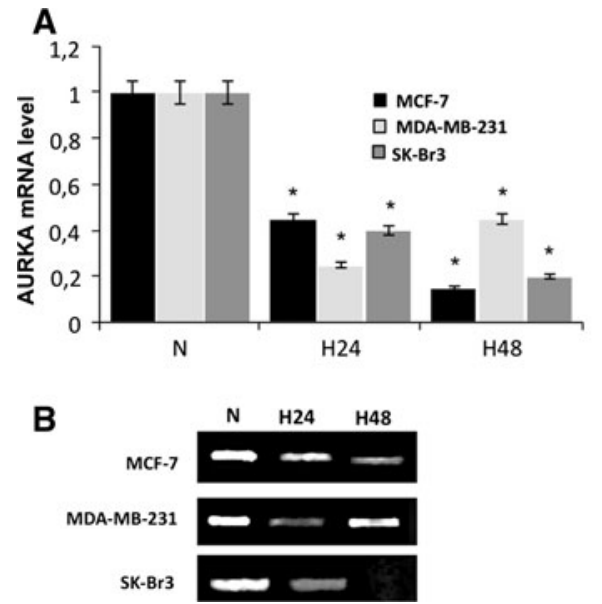

Fig. 3 Effects of hypoxia on AURKA expression in breast cancer cell lines. a Validation of microarray data by quantitative real-time PCR analysis. Changes in AURKA mRNA expression levels were determined in MCF-7, MDA-MB-231, and SKBr3 cells exposed to hypoxia $\left(3 \% \mathrm{O}_{2}\right)$ for 24 and $48 \mathrm{~h}$ with respect to control condition (normoxia, $16 \% \mathrm{O}_{2}$ ). Relative transcript levels were determined using the $2^{-\Delta \Delta C t}$ method and normalized to $\beta$-actin mRNA (endogenous control). Normoxic condition values are taken as 1 and hypoxic condition values represent fold decrease relative to control condition. Data are presented as fold changes \pm SDs. Significant difference, hypoxia for $24 \mathrm{~h}(\mathrm{H} 24)$ or for $48 \mathrm{~h}(\mathrm{H} 48)$ versus normoxia $(N)$,

in MDA-MB-231 cells. Furthermore, in all three BC cell lines, WB analysis showed a substantial hypoxia-mediated up-regulation of VEGF-A in the absence of siHIF-1 $\alpha$ and a considerable reduction in protein expression levels in cells transfected with siHIF-1 $\alpha$ (Fig. 4c).

At the same time, in order to further assess the HIF-1 potential role in regulation of hypoxia-mediated AURKA expression, BC cells were treated with DMOG, a cell-permeable inhibitor of both proline and asparaginyl
$* P<0.05$. b Quantification of AURKA mRNA expression using RTPCR analysis. c Effects of hypoxia on VEGF, AURKA, p-AURKA, and HIF- $1 \alpha$ protein expression levels in MCF-7, MDA-MB-231, and $\mathrm{SKBr} 3$ cells. Protein expression was examined by Western Blot analysis with the indicated antibodies, by developing with the enhanced chemiluminescence reagent (ECL). p-AURKA represents phospho-aurora A (Thr288). The GAPDH house-keeping protein was used as loading control. The experiments were performed at least three different times and the results were always similar. $N$ normoxia; $H 24$ hypoxia for $24 \mathrm{~h}$; $H 48$ hypoxia for $48 \mathrm{~h}$

hydroxylases able to induce HIF- $1 \alpha$ stabilization in normoxia. Thus, treatment of MCF-7, MDA-MB-231, and SKBr3 cells with a PHD inhibitor (for 24 and $48 \mathrm{~h}$ ) caused the activation of the HIF-1 pathway in normoxia. In fact, WB analysis provided results comparable to those previously described, leading to an increase in HIF- $1 \alpha$ expression levels and concomitant reduction of AURKA expression in the presence of DMOG. Interestingly, in MDA-MB-231 cells, a lower HIF-1 $\alpha$ induction was observed after $48 \mathrm{~h}$ of 

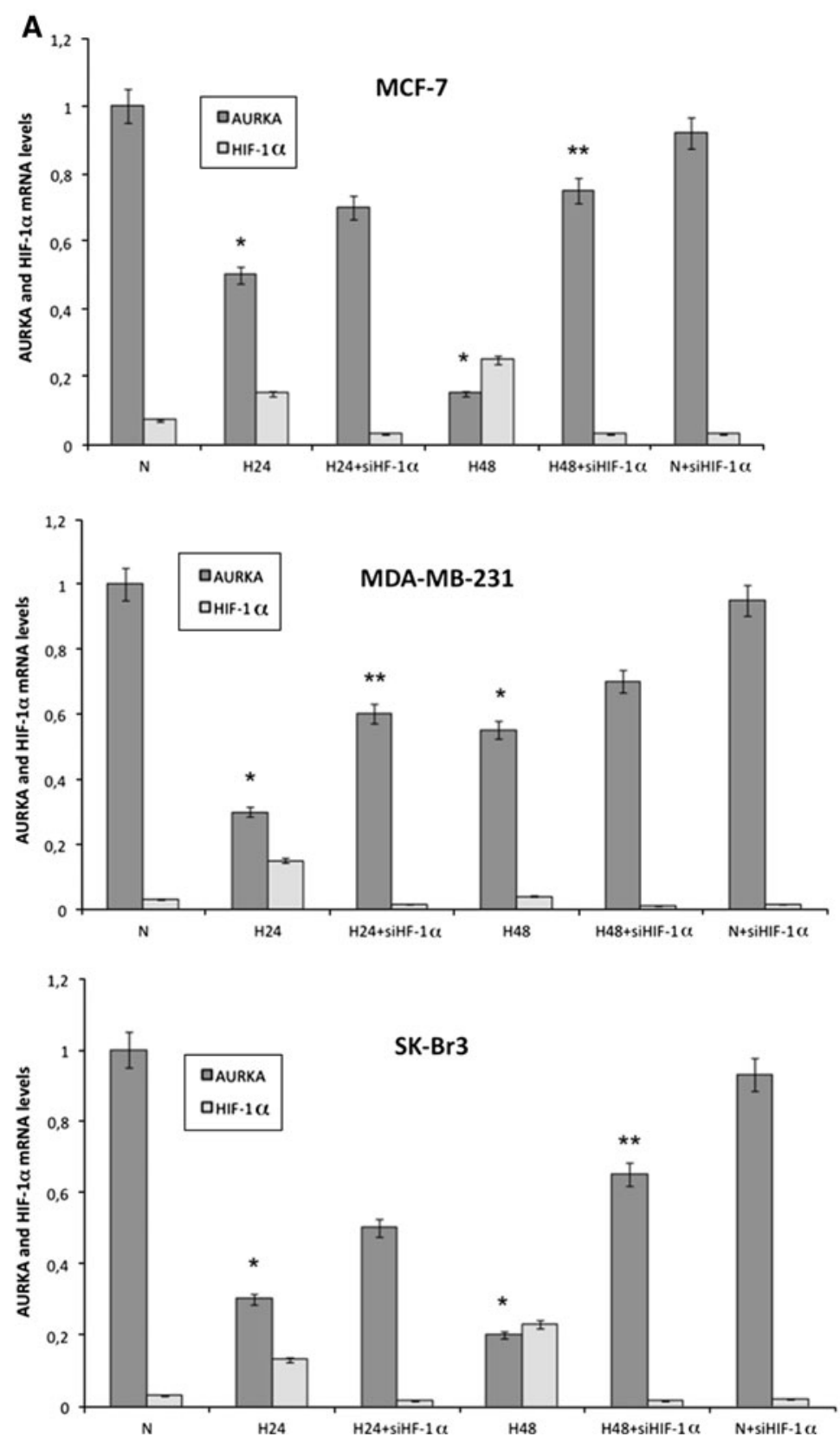

B
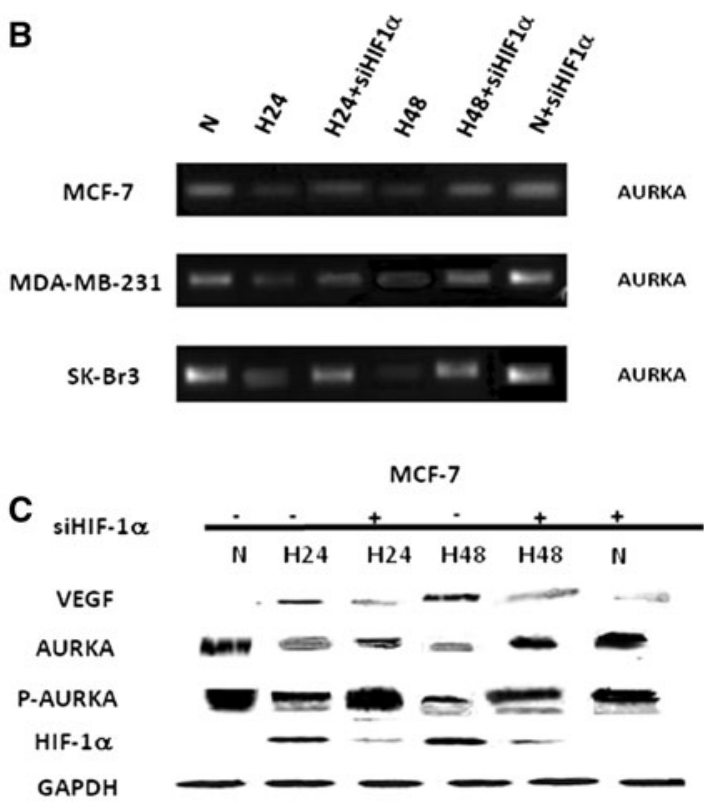

siHIF-1 $\alpha$

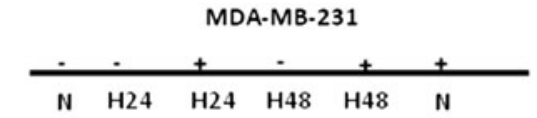

VEGF

AURKA

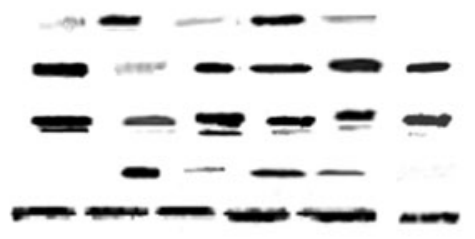

GAPDH
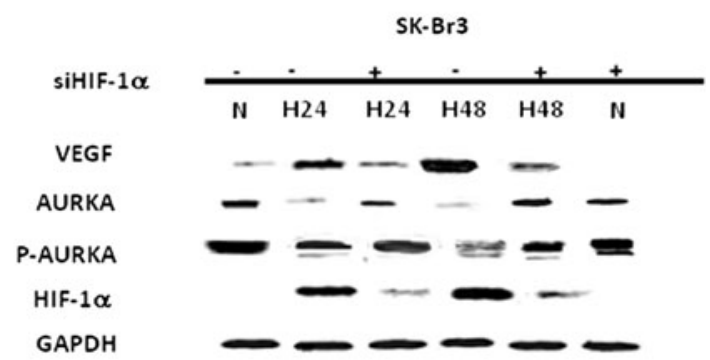

Fig. 4 Effects of HIF- $1 \alpha$ silencing on AURKA expression in breast cancer cells under hypoxic conditions. MCF-7, MDA-MB-231, and SKBr3 cells were transfected with a siRNA pool targeting HIF- $1 \alpha$ $($ siHIF- $1 \alpha)$ and subsequently exposed to hypoxia $\left(3 \% \mathrm{O}_{2}\right)$ for 24 and $48 \mathrm{~h}$. For all experiments, a non-targeting control pool was used as a siRNA negative control (data not shown). a Specific knockdown of HIF$1 \alpha$ was confirmed at the mRNA level using qRT-PCR analysis. Variations in AURKA and $H I F-1 \propto$ mRNA expression levels with respect to control condition (normoxia, $16 \% \mathrm{O}_{2}$ ) were evaluated in breast cancer cells with and without siHIF-1 $\alpha$. Relative transcript levels were determined using the $2^{-\Delta \Delta C t}$ method and normalized to $\beta$-actin mRNA (endogenous control). Data are presented as fold changes \pm SDs. AURKA

incubation with DMOG with respect to treatment for $24 \mathrm{~h}$, and a partial recovery of AURKA expression was detected (Fig. 5).
mRNA expression values are in linear scale, while those of $H I F-1 \alpha$ are in logarithm scale. Significant differences: hypoxia for $24 \mathrm{~h}$ (H24) or for $48 \mathrm{~h}(\mathrm{H} 48)$ versus normoxia $(N), * P<0.05 ; \mathrm{H} 24+$ siHIF- $1 \alpha$ versus $\mathrm{H} 24$, or $\mathrm{H} 48+$ siHIF- $1 \alpha$ versus $\mathrm{H} 48, * * P<0.05$. b Quantification of AURKA mRNA expression after HIF- $1 \alpha$ silencing using RT-PCR analysis. $\mathbf{c}$ Effects of HIF- $1 \alpha$ silencing on VEGF, AURKA, p-AURKA, and HIF- $1 \alpha$ protein expression levels in breast cancer cells transfected $(+)$ or not $(-)$ with siHIF-1 $\alpha$. Specific knockdown of HIF-1 $\alpha$ was assessed at the protein level by Western Blot analysis. p-AURKA represents phospho-aurora A (Thr288). The GAPDH protein was used as a loading control. The experiments were performed at least three different times and the results were always similar

According to these results, we suggest that HIF-1 could act directly or indirectly as a possible negative regulator of AURKA expression in $\mathrm{BC}$ cell lines cultured in hypoxic conditions. 


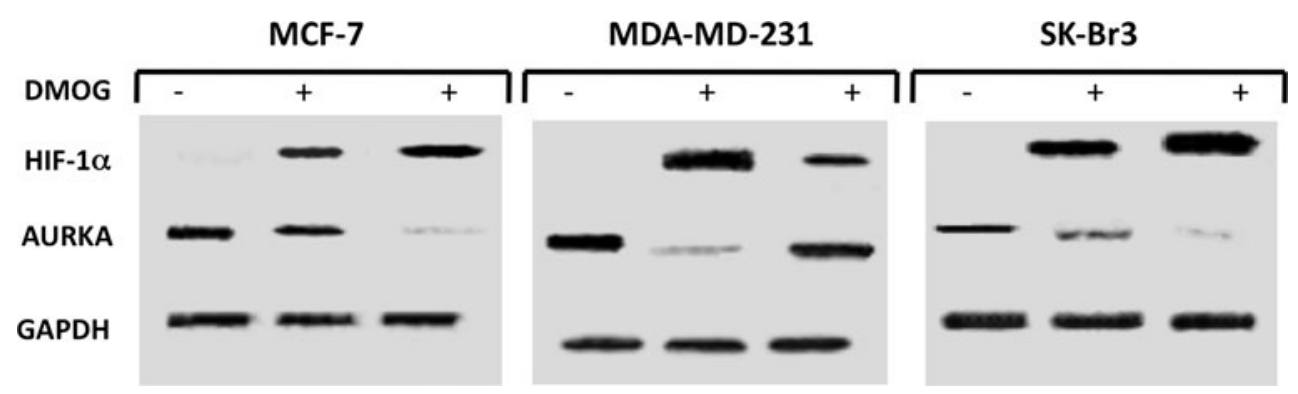

Fig. 5 Effects of HIF- $1 \alpha$ stabilization on AURKA expression. MCF7, MDA-MB-231, and SKBr3 cells were incubated in the absence $(-)$ or the presence $(+)$ of $1 \mathrm{mM}$ DMOG for $24 \mathrm{~h}(\mathrm{H} 24)$ and $48 \mathrm{~h}(\mathrm{H} 48)$ in normoxic conditions. Cells were lysed and protein extracts were

Involvement of HIF- $1 \alpha$ in transcriptional regulation of AURKA

Since previously obtained results suggest that HIF- $1 \alpha$ could mediate AURKA down-regulation in $\mathrm{BC}$ cells under hypoxia, we aimed to obtain new insights into the regulation of AURKA expression. Therefore, we investigated the role of HIF-1 as hypothetical transcriptional repressor of the AURKA promoter. HIF-1 regulates the transcription of its target genes usually via binding to HREs. Sequence analysis identified three putative HREs sites into AURKA proximal promoter (HRE-1: -336/-332; HRE-2: -323/ -319; and HRE-3: -240/-236) [14]. Thus, a ChIP assay was performed using an antibody against HIF- $1 \alpha$ in BC cells exposed to hypoxia, in order to evaluate the effects of hypoxia on HIF-1 $\alpha$ binding to the HREs into the proximal region of AURKA promoter. Then, quantitative PCR analysis, performed with specific primers for the AURKA promoter fragment containing the three HREs, revealed that HIF- $1 \alpha$ binds to the AURKA promoter. This analysis showed that HIF- $1 \alpha$ does not bind AURKA promoter in MCF-7, MDA-MB-231, and SKBr3 cells under normoxia. However, this binding was enhanced after hypoxic exposure for 24 and $48 \mathrm{~h}$ in MCF-7 and SKBr3 cells and maximal binding was observed after $48 \mathrm{~h}$ of hypoxia. Differently, increased binding was detected in MDA-MB231 cells after $24 \mathrm{~h}$ of hypoxia followed by an evident reduction after $48 \mathrm{~h}$ (Fig. 6). The reduced HIF-1 $\alpha$ binding to AURKA promoter region, observed after $48 \mathrm{~h}$ of hypoxia in MDA-MB-231 cells, supports our hypothesis because, in response to a decreased binding, we found an increase in mRNA and protein levels of AURKA and p-AURKA. These results nicely correlate with those previously obtained from gene and protein expression analyses.

Also, in order to further investigate whether hypoxia was involved in regulation of AURKA promoter activity, we performed a luciferase reporter assay. For this purpose, an AURKA promoter fragment containing three putative HREs was cloned into pGL3 vector at the sites between analyzed by Western Blot analysis, in order to assess HIF- $1 \alpha$ stabilization and AURKA expression levels. GAPDH protein was used as a loading control

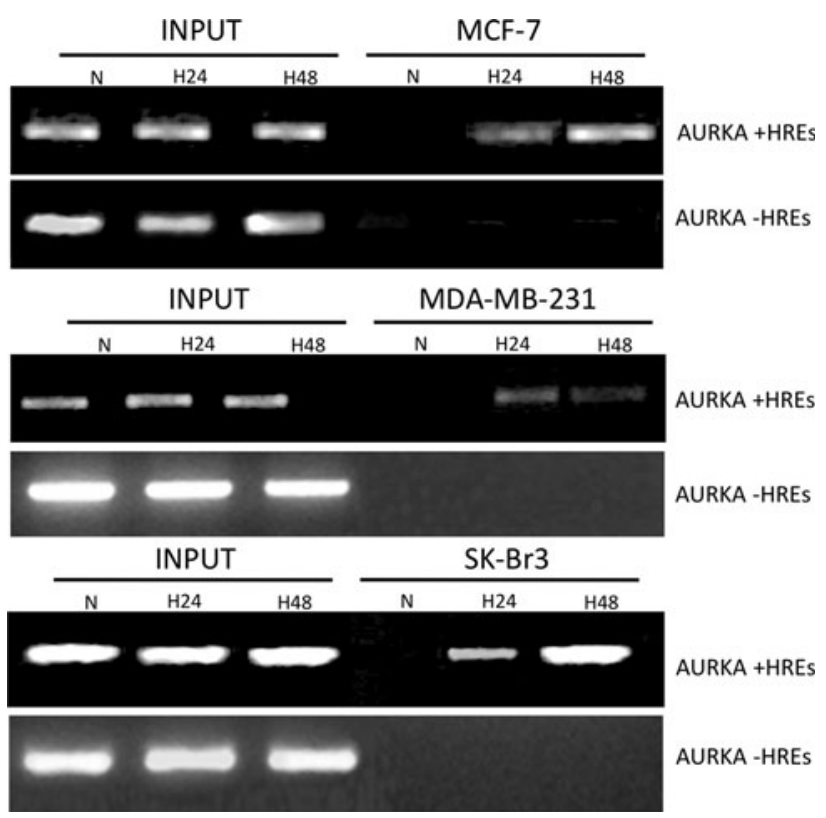

Fig. 6 Effects of hypoxia on HIF- $1 \alpha$ binding to proximal region of AURKA promoter. The binding of HIF- $1 \alpha$ to the proximal region $(-336 /-236)$ of $A U R K A$ promoter was tested by ChIP assay (as described in "Methods" section) using an antibody against HIF- $1 \alpha$ in MCF-7, MDA-MB-231, and SKBr3 breast cancer cells cultured in normoxic $\left(\begin{array}{lll}16 & \% & \mathrm{O}_{2}\end{array}\right)$ and hypoxic $\left(3 \% \mathrm{O}_{2}\right.$, for 24 and $\left.48 \mathrm{~h}\right)$ conditions. Interaction between HIF- $1 \alpha$ and AURKA promoter region containing HRE-1, HRE-2, and HRE-3 (AURKA + HREs) was analyzed by q-PCR. An AURKA promoter region containing no HREs was used as a control (AURKA-HREs). $N$ normoxia; $H 24$ hypoxia for $24 \mathrm{~h}$; $H 48$ hypoxia for $48 \mathrm{~h}$

KpnI and XhoI giving the pGL3-AURKA-Luc plasmidic construct. BC cells were transfected with this construct and luciferase activity was measured after incubation under normoxia and hypoxia. We found that luciferase activity was significantly decreased in MCF-7, MDA-MB-231, and SKBr3 cells transfected with pGL3-AURKA-Luc and incubated in hypoxia (for 24 and $48 \mathrm{~h}$ ) compared to cells transfected with empty vector (pGL3-basic-Luc), suggesting a hypoxia-mediated reduction of AURKA promoter activity (Fig. 7a). 

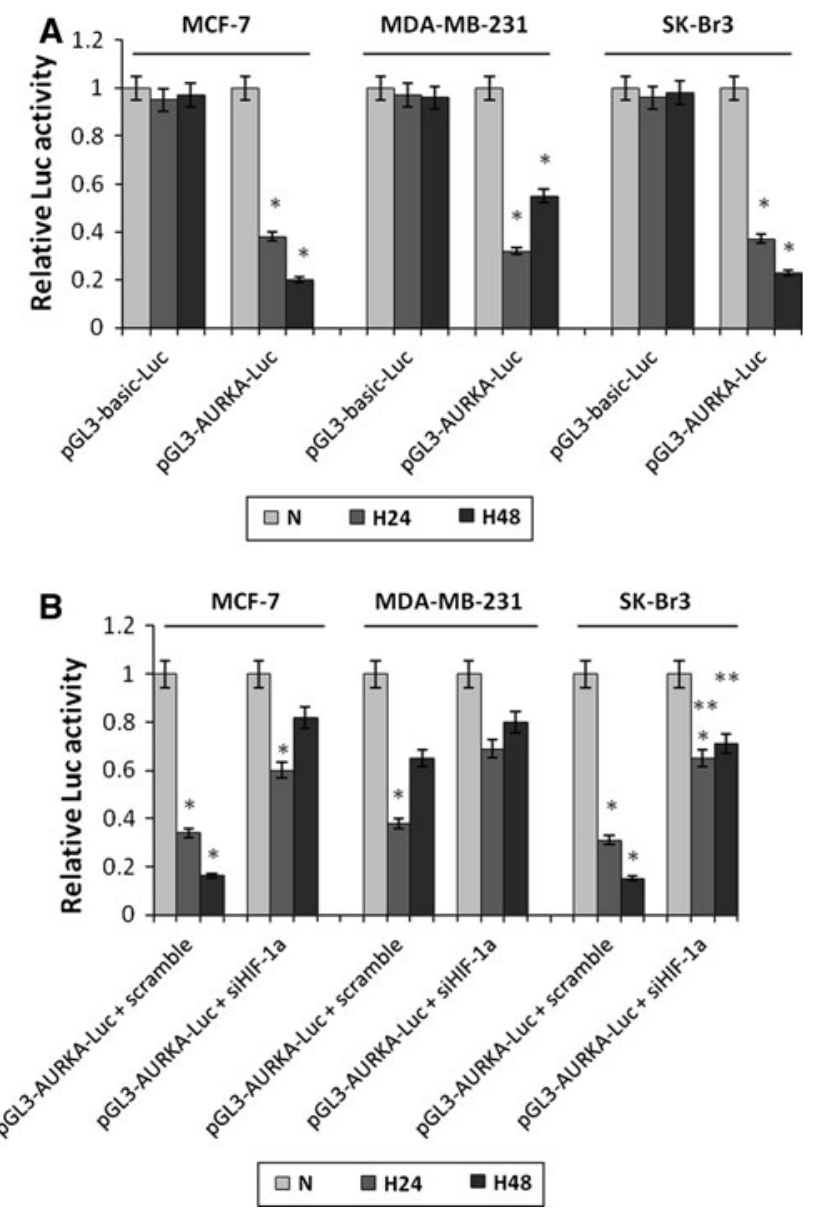

Fig. 7 Regulation of AURKA promoter activity under hypoxia. Transcriptional activity of AURKA promoter under hypoxia was evaluated by luciferase assay using the following plasmidic vectors: pGL3-AURKA-Luc, pGL3-basic-Luc (negative control), and pRLTK. Firefly luciferase activity was normalized to Renilla luciferase activity. Luciferase activity of cell lysates was determined by the Dual-Luciferase ${ }^{\circledR}$ Reporter Assay System (Promega). Data represent mean \pm SD from triplicate sets. Normalized luciferase activity in the respective controls was set to 1 . a Breast cancer cells were cotransfected with the pGL3-AURKA-Luc firefly luciferase vector and pRL-TK Renilla luciferase vector or with the pGL3-basic-Luc empty vector and, after $24 \mathrm{~h}$, incubated under normoxia or hypoxia (for 24 and $48 \mathrm{~h}$ ). Significant difference, hypoxia for $24 \mathrm{~h}$ (H24) or for $48 \mathrm{~h}$ $(\mathrm{H} 48)$ versus normoxia $(\mathrm{N}), * P<0.05$. b Cells were co-transfected with the pGL3-AURKA-Luc construct and a specific siRNA pool targeting HIF- $1 \alpha$ (siHIF-1 $\alpha$ ) as well as pRL-TK vector and, after $24 \mathrm{~h}$, incubated under normoxia or hypoxia (for 24 and $48 \mathrm{~h}$ ). A nontargeting control pool (scramble) was co-transfected as a siRNA negative control. *Significant difference, $\mathrm{H} 24$ or $\mathrm{H} 48$ versus $N$ in each experimental condition and **significant difference, H24 pGL3AURKA-Luc + siHIF- $1 \alpha$ versus H24 pGL3-AURKA-Luc + scramble and H48 pGL3-AURKA-Luc + siHIF-1 $\alpha$ versus H48 pGL3AURKA-Luc + scramble, $P<0.05$

Furthermore, to evaluate the possible HIF-1 role in regulation of AURKA promoter activity, a specific siRNA pool targeting HIF- $1 \alpha$ (siHIF- $1 \alpha$ ) was co-transfected with pGL3AURKA-Luc plasmid in BC cells and a siRNA scramble was used as a negative control. After co-transfection, cells were incubated under normoxia and hypoxia, and luciferase activity was determined. We observed that cells transfected with siHIF- $1 \alpha$ showed an increase of luciferase activity compared to cells transfected with negative control (scramble), indicating a higher induction of AURKA promoter activity after HIF-1 $\alpha$ knockdown. In particular, HIF$1 \alpha$-silenced MCF-7 and SKBr3 cells showed a higher increase of AURKA promoter activity after $48 \mathrm{~h}$ of hypoxia (Fig. 7b). Therefore, these data suggest that HIF-1 $1 \alpha$ could be involved in the negative regulation of AURKA expression, indicating a new possible transcriptional role of HIF-1 in BC cell lines.

\section{Discussion}

Nowadays, although oncologists have several available options (chemotherapy, hormone therapy, and biologic agents such as anti-angiogenic and anti-HER2 drugs), BC is still responsible for a significant percentage of cancer deaths in women [43, 44].

Hypoxia is a typical feature of the microenvironment of several solid tumors and is associated with poor prognosis in several cancer types, including BC [45]. Since tumor hypoxia is known to be an important factor for the expression of many genes involved in tumorigenesis and cell cycle regulation [46], we performed a microarraybased gene expression analysis in order to determine different expression profiles in MCF-7, MDA-MB-231, and $\mathrm{SKBr} 3 \mathrm{BC}$ cells in response to hypoxia for 24 and $48 \mathrm{~h}$. This study allowed us to identify a set of 270 DEGs in hypoxia common to three BC cell lines. Our attention was focused mainly on the genes showing a significant variation in expression levels involved in proliferation, cell cycle progression and regulation, mitosis, and response to hypoxia. Three main molecular pathways were found altered in BC cell lines after hypoxia for 24 and $48 \mathrm{~h}$ : cell cycle regulation, HIF-1 $\alpha$ network, and AURKA signaling. Among the DEGs involved in proliferation and cell cycle control, CDKN1A (p21 $\left.{ }^{\mathrm{Cip} 1}\right)$, that can elicit the G1/S checkpoint, was up-regulated, while genes that further determine entry from $\mathrm{G} 1$ to S-phase, including $C D C 6$, $C C N D 1, C C N E 2$, and $C D K 2$, were tendentially decreased in expression. Furthermore, $C D C 25 \mathrm{~A}$ was down-regulated in MCF-7 and SKBr3 cells and up-regulated in MDA-MB231 cells. Concomitant with decreased G1 to S-phase progression, a reduced expression of genes that regulate the passage of cells through $\mathrm{G} 2 / \mathrm{M}$, such as $C C N A 2, C C N B 1$, $C C N B 2, C D C 2$ (CDK1), and $C D C 25 C$, was also demonstrated in MCF-7 and SKBr3 cells exposed to hypoxia for 24 and $48 \mathrm{~h}$, and in MDA-MB-231 cells under hypoxia for $24 \mathrm{~h}$. In addition, among the DEGs involved in HIF-1 $\alpha$ network, VEGF-A, SLC2A1, JUN, FOS, and other genes 
encoding for glycolytic enzymes ( $P G K 1, P F K F B 3, H K 2$, $A L D O A)$ were up-regulated in all three analyzed $\mathrm{BC}$ cell lines. Finally, genes that regulate the mitosis included in AURKA signaling pathway, such as AURKA, AURKB, $J U B$ (ajuba), and TPX2, showed a significant down-regulation in expression levels. These changes could be responsible for genomic instability in BC. For the first time, our study showed that hypoxia induces a noteworthy down-regulation of AURKA expression in BC cell lines. The Aurora family kinases, especially aurora-A, play a particularly important role in the cell cycle and their deregulated expression is involved in many types of human malignancies [47, 48]. Several studies showed that auroraA overexpression correlates with tumorigenesis, metastasis, and chemoresistance, confirming its pro-survival function in cancer cells [49-51]. Although in the literature there is evidence describing the activation of AURKA in different tumors, the mechanism of transcriptional upregulation of $A U R K A$ in human $\mathrm{BC}$ is not yet elucidated [15]. Thus, the understanding of the regulatory pathways that mediate a reduced transcription of $A U R K A$ could be important, in order to identify new possible mechanisms counteracting not only BC progression but also the development of other tumors associated with AURKA overexpression. Therefore, our work focused mainly on effects of hypoxia on AURKA expression in BC cells and molecular mechanisms that regulate this. MCF-7, MDA-MB-231, and SKBr3 cells, in response to hypoxia for 24 and $48 \mathrm{~h}$, showed a down-regulation of AURKA expression compared to normoxic condition, with a partial increase of expression after $48 \mathrm{~h}$ only in MDA-MB-231 cells. Moreover, microarray analysis revealed a parallel decrease in expression levels of $A U R K B$ and two AURKA co-activators, JUB and $T P X 2$. However, according to the recovery of $A U R K A$ expression, $A U R K B$ and $T P X 2$ exhibited positive fold change in MDA-MB-231 cells exposed to hypoxia for $48 \mathrm{~h}$, and $J U B$ showed a partial increase of expression with respect to hypoxic condition at $24 \mathrm{~h}$. Further analyses at protein level confirmed that hypoxia induces a decreased expression of AURKA, with an increased reduction of expression levels after $48 \mathrm{~h}$ of exposure to hypoxia in MCF-7 and SKBr3 cells, and with an initial decrease after $24 \mathrm{~h}$ followed by a partial recovery of expression after $48 \mathrm{~h}$ in MDA-MB-231 cells. Together with the reduction of the AURKA protein expression, an increase in HIF- $1 \alpha$ and VEGF-A protein levels was observed. However, HIF-1 $\alpha$ showed a lower expression level in MDA-MB-231 cells exposed to hypoxia for $48 \mathrm{~h}$. From these data, HIF-1 $\alpha$ expression seems to be inversely related to AURKA expression.

Since HIF-1 $\alpha$ plays a pivotal role in the homeostatic mechanisms involved in the cellular response to hypoxic stress, we investigated its role in AURKA down-regulation in $\mathrm{BC}$ cells exposed to hypoxia. To determine whether AURKA down-regulation was caused by increased expression of HIF- $1 \alpha$ in hypoxia, variations in AURKA expression were evaluated, both at mRNA and protein level, in BC cells transfected with a specific siRNA pool targeting HIF-1 $\alpha$ (siHIF-1 $\alpha)$. Thus, HIF-1 $\alpha$-dependent effects of hypoxic exposure were reversed by siRNAmediated silencing of HIF-1 $\alpha$. Our data suggest that HIF$1 \alpha$ could be involved in the regulation of AURKA expression in hypoxia because expression of siRNA against HIF- $1 \alpha$ reduced the down-regulation of AURKA in BC cell lines. In MCF-7 and SKBr3 cells, specific knockdown of HIF- $1 \alpha$ induced a greater difference of AURKA expression in hypoxia at $48 \mathrm{~h}$ in comparison to that detected at $24 \mathrm{~h}$. In MDA-MB-231 cells, a lower difference was observed at $48 \mathrm{~h}$ with respect to that found at $24 \mathrm{~h}$. At the same time, cells were treated with DMOG that induces an increase in HIF-1 $\alpha$ expression levels in normoxia, by inhibiting the PHDs. A lower AURKA expression was found in correspondence to higher HIF-1 $\alpha$ expression levels. These findings suggest that hypoxia could down-regulate $A U R K A$ expression in a HIF-1 $\alpha$-dependent manner in BC cell lines. Since the molecular mechanisms through which AURKA is regulated in response to hypoxic condition are unknown in $\mathrm{BC}$, the overall goal of this investigation was to obtain new insights on the regulation of AURKA expression in $\mathrm{BC}$ cells cultured under normoxia and hypoxia, by evaluating the possible HIF-1 role in transcriptional control of AURKA expression. HIF-1 regulates the transcription of its target genes usually via binding to HREs. Three putative HREs sites were identified into AURKA proximal promoter. In hepatocellular carcinoma, the stabilization of HIF-1 $\alpha$ not only induces the expression of genes involved in angiogenesis, glucidic metabolism, and survival but also causes AURKA up-regulation via its hypoxia-dependent binding to the HREs [14]. Moreover, in 2010, Xu et al. [52] reported that $V H L$ inactivation stabilizes HIF-1 $\alpha$ inducing AURKA up-regulation in clear cell renal cell carcinoma (CCRCC) cell lines. Unlike the previous findings, we hypothesize a new possible mechanism where HIF-1 rather than inducing transcriptional activation could promote the AURKA downregulation via its binding to HREs into proximal region of AURKA promoter in BC cells under hypoxia. Therefore, we investigated the potential role of HIF-1 as hypothetical transcriptional repressor of the $A U R K A$ promoter in the three BC cell lines. Our study showed that HIF-1 $\alpha$ does not bind to the AURKA promoter region containing three HREs in $\mathrm{BC}$ cells under normoxia, but its binding is enhanced after hypoxic exposure for 24 and $48 \mathrm{~h}$ in MCF-7 and SKBr3 cells, and a maximal binding is observed after $48 \mathrm{~h}$ of hypoxia. Differently, MDA-MB-231 cells showed an increased binding after $24 \mathrm{~h}$ of hypoxia followed by an evident reduction after $48 \mathrm{~h}$. Our analyses indicated that 
MDA-MB-231 cells show a different behavior concerning the AURKA expression after $48 \mathrm{~h}$ of hypoxia with respect to MCF-7 and SKBr3 cells. This could be attributed to a different expression level of HIF-1 $\alpha$ that binds to a lesser extent the AURKA promoter. Therefore, in support of our hypothesis, the increased HIF-1 $\alpha$ binding into the proximal region of $A U R K A$ promoter is related to a decrease in gene and protein expression levels of AURKA. Furthermore, to investigate whether HIF-1 regulates AURKA expression in hypoxia, luciferase assays were performed, showing a partial recovery of $A U R K A$ promoter activity after HIF-1 $\alpha$ knockdown. Therefore, these results suggest a new possible transcriptional role of HIF-1 that could determine a negative control of AURKA expression in $\mathrm{BC}$ cell lines under hypoxia. If HIF-1 acts directly as a possible transcriptional repressor of AURKA inhibiting the binding of RNA Polymerase II to its own site, or indirectly, preventing the binding of a transcriptional activator is yet unknown. This will be the subject of our future research as well as for a better understanding of the molecular bases of this downregulation, by evaluating whether HIF-1 alone is directly involved in transcriptional control of AURKA in hypoxia or if other co-repressor proteins are implicated.

For the first time, the present study shows that hypoxia directly links HIF-1 with AURKA expression in $\mathrm{BC}$, highlighting a possible pathophysiological role of this new pathway in this tumor and confirming HIF-1 as an important player linking an environmental signal to the AURKA promoter. Since AURKA is a key regulator of the chromosomal segregation process in mammalian cells and its down-regulation overrides the estrogen-mediated growth and chemoresistance in BC cells [53], these results could provide innovative approaches for the development of novel possible therapeutic strategies against BC.

Conflict of interest The authors declare no conflict of interest.

Ethical standards The authors declare that the experiments comply with the current laws.

\section{References}

1. Lech R, Przemyslaw O (2011) Epidemiological models for breast cancer risk estimation. Ginekol Pol 82(6):451-454

2. Alvarez RH, Valero V, Hortobagyi GN (2010) Emerging targeted therapies for breast cancer. J Clin Oncol 28(20):3366-3379. doi:10.1200/JCO.2009.25.4011

3. Sorlie T, Perou CM, Tibshirani R, Aas T, Geisler S, Johnsen H, Hastie T, Eisen MB, van de Rijn M, Jeffrey SS, Thorsen T, Quist H, Matese JC, Brown PO, Botstein D, Lonning PE, BorresenDale AL (2001) Gene expression patterns of breast carcinomas distinguish tumor subclasses with clinical implications. Proc Natl Acad Sci USA 98(19):10869-10874. doi:10.1073/pnas. 191367098
4. Whitfield ML, Sherlock G, Saldanha AJ, Murray JI, Ball CA, Alexander KE, Matese JC, Perou CM, Hurt MM, Brown PO, Botstein D (2002) Identification of genes periodically expressed in the human cell cycle and their expression in tumors. Mol Biol Cell 13(6):1977-2000. doi:10.1091/mbc.02-02-0030

5. Liu J, Campen A, Huang S, Peng SB, Ye X, Palakal M, Dunker AK, Xia Y, Li S (2008) Identification of a gene signature in cell cycle pathway for breast cancer prognosis using gene expression profiling data. BMC Med Genomics 1:39. doi:10.1186/1755-8794-1-39

6. Golias CH, Charalabopoulos A, Charalabopoulos K (2004) Cell proliferation and cell cycle control: a mini review. Int J Clin Pract 58(12):1134-1141

7. Williams GH, Stoeber K (2012) The cell cycle and cancer. J Pathol 226(2):352-364. doi:10.1002/path.3022

8. Fu J, Bian M, Jiang Q, Zhang C (2007) Roles of aurora kinases in mitosis and tumorigenesis. Mol Cancer Res 5(1):1-10. doi:10. 1158/1541-7786.MCR-06-0208

9. Vader G, Lens SM (2008) The aurora kinase family in cell division and cancer. Biochim Biophys Acta 1786(1):60-72. doi:10.1016/j.bbcan.2008.07.003

10. Barr AR, Gergely F (2007) Aurora-A: the maker and breaker of spindle poles. J Cell Sci 120(Pt 17):2987-2996. doi:10.1242/jcs. 013136

11. El-Rifai W, Frierson HF Jr, Harper JC, Powell SM, Knuutila S (2001) Expression profiling of gastric adenocarcinoma using cDNA array. Int J Cancer 92(6):832-838. doi:10.1002/ijc.1264

12. Tanaka T, Kimura M, Matsunaga K, Fukada D, Mori H, Okano Y (1999) Centrosomal kinase AIK1 is overexpressed in invasive ductal carcinoma of the breast. Cancer Res 59(9):2041-2044

13. Sen S, Zhou H, Zhang RD, Yoon DS, Vakar-Lopez F, Ito S, Jiang F, Johnston D, Grossman HB, Ruifrok AC, Katz RL, Brinkley W, Czerniak B (2002) Amplification/overexpression of a mitotic kinase gene in human bladder cancer. J Natl Cancer Inst 94(17):1320-1329

14. Klein A, Flugel D, Kietzmann T (2008) Transcriptional regulation of serine/threonine kinase-15 (STK15) expression by hypoxia and HIF-1. Mol Biol Cell 19(9):3667-3675. doi:10.1091/ mbc.E08-01-0042

15. Wu CC, Yang TY, Yu CT, Phan L, Ivan C, Sood AK, Hsu SL, Lee MH (2012) p53 negatively regulates aurora A via both transcriptional and posttranslational regulation. Cell Cycle 11(18):3433-3442. doi:10.4161/cc.21732

16. Lehman NL, O'Donnell JP, Whiteley LJ, Stapp RT, Lehman TD, Roszka KM, Schultz LR, Williams CJ, Mikkelsen T, Brown SL, Ecsedy JA, Poisson LM (2012) Aurora A is differentially expressed in gliomas, is associated with patient survival in glioblastoma and is a potential chemotherapeutic target in gliomas. Cell Cycle 11(3):489-502. doi:10.4161/cc.11.3.18996

17. Agnese V, Bazan V, Fiorentino FP, Fanale D, Badalamenti G, Colucci G, Adamo V, Santini D, Russo A (2007) The role of aurora-A inhibitors in cancer therapy. Ann Oncol 18(Suppl 6):47-52. doi:10.1093/annonc/mdm224

18. Rademakers SE, Span PN, Kaanders JH, Sweep FC, van der Kogel AJ, Bussink J (2008) Molecular aspects of tumour hypoxia. Mol Oncol 2(1):41-53. doi:10.1016/j.molonc.2008.03. 006

19. Brown JM (2002) Tumor microenvironment and the response to anticancer therapy. Cancer Biol Ther 1(5):453-458

20. Semenza G (2002) Signal transduction to hypoxia-inducible factor 1. Biochem Pharmacol 64(5-6):993-998

21. Knowles HJ, Harris AL (2001) Hypoxia and oxidative stress in breast cancer. Hypoxia and tumourigenesis. Breast Cancer Res 3(5):318-322

22. Wenger A, Kowalewski N, Stahl A, Mehlhorn AT, Schmal H, Stark GB, Finkenzeller G (2005) Development and characterization of a spheroidal coculture model of endothelial cells and 
fibroblasts for improving angiogenesis in tissue engineering. Cells Tissues Organs 181(2):80-88. doi:10.1159/000091097

23. Schwab LP, Peacock DL, Majumdar D, Ingels JF, Jensen LC, Smith KD, Cushing RC, Seagroves TN (2012) Hypoxia-inducible factor $1 \alpha$ promotes primary tumor growth and tumor-initiating cell activity in breast cancer. Breast Cancer Res 14(1):R6. doi:10. 1186/bcr3087

24. Pugh CW, Gleadle J, Maxwell PH (2001) Hypoxia and oxidative stress in breast cancer. Hypoxia signalling pathways. Breast Cancer Res 3(5):313-317

25. Kimbro KS, Simons JW (2006) Hypoxia-inducible factor-1 in human breast and prostate cancer. Endocr Relat Cancer 13(3):739-749. doi:10.1677/erc. 1.00728

26. Vaupel P (2004) The role of hypoxia-induced factors in tumor progression. Oncologist 9(suppl 5):10-17. doi:10.1634/theoncologist. 9-90005-10

27. Peurala E, Koivunen P, Bloigu R, Haapasaari KM, Jukkola-Vuorinen A (2012) Expressions of individual PHDs associate with good prognostic factors and increased proliferation in breast cancer patients. Breast Cancer Res Treat 133(1):179-188. doi:10. 1007/s10549-011-1750-5

28. Kaelin WG Jr (2003) The von Hippel-Lindau gene, kidney cancer, and oxygen sensing. J Am Soc Nephrol 14(11):2703-2711

29. Manalo DJ, Rowan A, Lavoie T, Natarajan L, Kelly BD, Ye SQ, Garcia JG, Semenza GL (2005) Transcriptional regulation of vascular endothelial cell responses to hypoxia by HIF-1. Blood 105(2):659-669. doi:10.1182/blood-2004-07-2958

30. Hu CJ, Wang LY, Chodosh LA, Keith B, Simon MC (2003) Differential roles of hypoxia-inducible factor 1alpha (HIF1alpha) and HIF-2alpha in hypoxic gene regulation. Mol Cell Biol 23(24):9361-9374

31. Giatromanolaki A, Harris AL (2001) Tumour hypoxia, hypoxia signaling pathways and hypoxia inducible factor expression in human cancer. Anticancer Res 21(6):4317-4324

32. Yamamoto Y, Ibusuki M, Okumura Y, Kawasoe T, Kai K, Iyama K, Iwase $\mathrm{H}$ (2008) Hypoxia-inducible factor $1 \alpha$ is closely linked to an aggressive phenotype in breast cancer. Breast Cancer Res Treat 110(3):465-475. doi:10.1007/s10549-007-9742-1

33. Chen KF, Lai YY, Sun HS, Tsai SJ (2005) Transcriptional repression of human cad gene by hypoxia inducible factor- $1 \alpha$. Nucl Acids Res 33(16):5190-5198. doi:10.1093/nar/gki839

34. Feige E, Yokoyama S, Levy C, Khaled M, Igras V, Lin RJ, Lee S, Widlund HR, Granter SR, Kung AL, Fisher DE (2011) Hypoxiainduced transcriptional repression of the melanoma-associated oncogene MITF. Proc Natl Acad Sci USA 108(43):E924-E933. doi:10.1073/pnas.1106351108

35. Ryu K, Park C, Lee Y (2011) Hypoxia-inducible factor 1 alpha represses the transcription of the estrogen receptor alpha gene in human breast cancer cells. Biochem Biophys Res Commun 407(4):831-836. doi:10.1016/j.bbrc.2011.03.119

36. Federico M, Symonds CE, Bagella L, Rizzolio F, Fanale D, Russo A, Giordano A (2010) R-Roscovitine (seliciclib) prevents DNA damage-induced cyclin A1 upregulation and hinders nonhomologous end-joining (NHEJ) DNA repair. Mol Cancer 9:208. doi: 10.1186/1476-4598-9-208

37. Gautier L, Cope L, Bolstad BM, Irizarry RA (2004) Affyanalysis of Affymetrix GeneChip data at the probe level. Bioinformatics 20(3):307-315. doi:10.1093/bioinformatics/btg405
38. Irizarry RA, Hobbs B, Collin F, Beazer-Barclay YD, Antonellis KJ, Scherf U, Speed TP (2003) Exploration, normalization, and summaries of high density oligonucleotide array probe level data. Biostatistics 4(2):249-264. doi:10.1093/biostatistics/4.2.249

39. Smyth GK (2004) Linear models and empirical Bayes methods for assessing differential expression in microarray experiments. Stat Appl Genet Mol Biol 3, Article 3. doi:10.2202/1544-6115. 1027

40. Benjamini Y, Drai D, Elmer G, Kafkafi N, Golani I (2001) Controlling the false discovery rate in behavior genetics research. Behav Brain Res 125(1-2):279-284

41. Wettenhall JM, Simpson KM, Satterley K, Smyth GK (2006) affylmGUI: a graphical user interface for linear modeling of single channel microarray data. Bioinformatics 22(7):897-899. doi:10.1093/bioinformatics/bt1025

42. Kanehisa M, Goto S (2000) KEGG: kyoto encyclopedia of genes and genomes. Nucl Acids Res 28(1):27-30

43. DeSantis C, Siegel R, Bandi P, Jemal A (2011) Breast cancer statistics. CA Cancer J Clin 61(6):409-418. doi:10.3322/caac. 20134

44. van der Groep P, van Diest PJ, Smolders YH, Ausems MG, van der Luijt RB, Menko FH, Bart J, de Vries EG, van der Wall E (2013) HIF-1alpha overexpression in ductal carcinoma in situ of the breast in BRCA1 and BRCA2 mutation carriers. PLoS ONE 8(2):e56055. doi:10.1371/journal.pone.0056055

45. Favaro E, Lord S, Harris AL, Buffa FM (2011) Gene expression and hypoxia in breast cancer. Genome Med 3(8):55. doi:10.1186/ gm271

46. Kunz M, Ibrahim SM (2003) Molecular responses to hypoxia in tumor cells. Mol Cancer 2:23

47. Lens SM, Voest EE, Medema RH (2010) Shared and separate functions of polo-like kinases and aurora kinases in cancer. Nat Rev Cancer 10(12):825-841. doi:10.1038/nrc2964

48. Kitajima S, Kudo Y, Ogawa I, Tatsuka M, Kawai H, Pagano M, Takata T (2007) Constitutive phosphorylation of aurora-A on ser51 induces its stabilization and consequent overexpression in cancer. PLoS ONE 2(9):e944. doi:10.1371/journal.pone.0000944

49. Katayama H, Brinkley WR, Sen S (2003) The aurora kinases: role in cell transformation and tumorigenesis. Cancer Metastasis Rev 22(4):451-464

50. Wang LH, Xiang J, Yan M, Zhang Y, Zhao Y, Yue CF, Xu J, Zheng FM, Chen JN, Kang Z, Chen TS, Xing D, Liu Q (2010) The mitotic kinase aurora-A induces mammary cell migration and breast cancer metastasis by activating the Cofilin-F-actin pathway. Cancer Res 70(22):9118-9128. doi:10.1158/0008-5472. CAN-10-1246

51. Yang H, He L, Kruk P, Nicosia SV, Cheng JQ (2006) Aurora-A induces cell survival and chemoresistance by activation of Akt through a p53-dependent manner in ovarian cancer cells. Int $\mathbf{J}$ Cancer 119(10):2304-2312. doi:10.1002/ijc.22154

52. Xu J, Li H, Wang B, Xu Y, Yang J, Zhang X, Harten SK, Shukla D, Maxwell PH, Pei D, Esteban MA (2010) VHL inactivation induces HEF1 and aurora kinase A. J Am Soc Nephrol 21(12):2041-2046. doi:10.1681/ASN.2010040345

53. Lee HH, Zhu Y, Govindasamy KM, Gopalan G (2008) Downregulation of aurora-A overrides estrogen-mediated growth and chemoresistance in breast cancer cells. Endocr Relat Cancer 15(3):765-775. doi:10.1677/ERC-07-0213 